\title{
Distal Radius Fractures: Relationship between Radiologic Parameters and Functional Outcome
}

\author{
Niraj Ranjeet ${ }^{1,2}$ and Emmanuel P. Estrella ${ }^{1,2}$ \\ ${ }^{1}$ Microsurgery Unit, Department of Orthopedics, College of Medicine and Philippine General Hospital, University of the Philippines Manila \\ ${ }^{2}$ ASTRO (Advanced STudy and Research in Orthopedics) Study Group, National Institutes of Health, University of the Philippines Manila
}

\begin{abstract}
Background. Distal radius fractures (DRFs) are the most common fractures of the upper extremity. At present, it can be treated by various options that include closed reduction and cast, open reduction and internal fixation using plates and screws with or without Kirschner wires and external fixation. Thus, the primary objective of this study was to determine if the radiographic parameters, pain score and grip strength was associated with the Gartland and Werley's Functional Scoring System and Modified Mayo Scoring System functional scores. The secondary objective was to determine the association between the Gartland and Werley scores and the Modified Mayo scores.
\end{abstract}

Methods. We retrospectively reviewed 18 patients with distal radius fractures treated within 3 weeks of injury by closed reduction and casting, closed reduction and pinning or open reduction with internal or external fixation. Patients were followed up at 1.5 and 3 months and were evaluated in terms of functional scoring using the Gartland and Werley's and Modified Mayo Functional Scoring System.

Results. The radiological parameters improved from preoperative to immediate postoperative $x$-ray and all parameters remained the same until 3 months follow up. Grip strength improved from $50.3 \pm 18.1 \%$ of the contralateral at 1.5 months to $70.33 \pm 11.2 \%$ at 3 months follow up. This was significant $(p<0.05)$. There was no association between the $x$-ray score (Sarmiento's modification of the Lindstrom score) and the functional outcome scores of Modified Wrist Mayo and Gartland and Werley score ( $p=0.53$ and 0.21 , respectively). Overall, the average Modified Mayo wrist score was 77.5 and the average Gartland and Werley score was 2.1. A higher grip score was also associated with a higher Modified Mayo Wrist score $\left(r^{2}=0.51\right.$, $p=0.03)$ and a better Gartland and Werley Score $\left(r^{2}=-0.70\right.$, $\mathrm{p}=0.001)$. Lower pain scores were associated with a higher Modified Mayo Wrist score $\left(r^{2}=-0.52, p=0.03\right)$, but not with a better Gartland and Werley Score. Of 18 patients, two developed pin tract infection.

\footnotetext{
Corresponding author: Emmanuel P. Estrella, MD

Microsurgery Unit, Department of Orthopedics

Philippine General Hospital

University of the Philippines Manila

Taft Avenue, Ermita, Manila 1000 Philippines

Telephone: +632 5548466

Email: estee96@yahoo.com
}

Conclusion. We could not find any correlation between the radiologic scoring of distal radius fractures after treatment to the functional outcome scoring according to the Gartland and Werley and Modified Mayo score.

Key Words: distal radius fractures, functional outcome, radiologic outcome

\section{Introduction}

Distal radius fractures (DRF) represent the most common fractures of the upper extremity. The reported overall incidence was 280 to 440 per 100,000 individuals annually. As many as $20 \%$ to $50 \%$ of DRFs were considered inadequately reduced and require surgical fixation. ${ }^{1}$

Nondisplaced stable DRFs in physiologically inactive patients are usually immobilized for a minimal period of time and good result was still expected..$^{2-7}$ But for displaced, unstable fractures in active, young patients, a more aggressive approach such as internal or external fixation have been used. Regardless of the methods of fixation, the principles of reduction were to restore the articular congruity, radial height, radial tilt and volar tilt.

DRFs are recognized as complex injuries with variable prognosis depending on several variables, including the fracture type and method of treatment. Failure to reduce these fractures is associated with more subtle, late problems such as midcarpal instability, incongruity or instability of the distal radioulnar joint, ulnar impaction syndrome, post traumatic arthritis and pain syndromes secondary to small degrees of radial malalignment or intracarpal ligament disruption..$^{3-7}$ Although DRFs can cause substantial physical problems and financial burden to afflicted patients, factors that lead to good or poor outcomes after treatment have not been well characterized. ${ }^{1,8}$

One well-accepted concept is the importance of restoring articular congruity of displaced, intra-articular DRFs, especially in young active patients. ${ }^{4}$ Several studies have shown that restoring the articular surface favorably influences the functional outcome and decreases the incidence of posttraumatic arthrosis. ${ }^{8-11}$ Knirk and Jupiter ${ }^{12}$ in a clinical study of patients less than forty years old and with DRFs with intraarticular involvement, found that the prevalence of osteoarthritis and a poor functional outcome at a mean of 6.7 years after the injury was higher for fractures 
which healed with an incongruous radiocarpal joint than for those which healed with a congruous joint. Trumble et al. ${ }^{13}$ suggested that presence of step off and gap deformities, following operative treatment, tend to be associated with a worse functional and radiographic outcomes. Further on he says it has been difficult to demonstrate conclusively that reduction of displaced fracture fragments reduces the rate of posttraumatic osteoarthritis and leads to improved clinical results. However, other authors conclude that despite progression of arthrosis patients shows a high level of function. There was no statistical correlation noted between radiographic or CT scan radiocarpal arthrosis and clinical function. ${ }^{4}$

In a study by Chung et al., ${ }^{1}$ the authors did not find any relationship between the following potential predictors identified in the literature as important factors influencing outcomes after DRF: hand dominance, gender, AO fracture classification, radial height, radial inclination, complications, ulnar styloid fracture, ulnar variance. Demographic or radiological parameters with greater influence in outcome was also in question, although restoration of articular congruity was given priority by most authors. , $12,14-17^{-17}$

The primary objective of this study was to determine the association of radiographic parameters, the overall acceptability of alignment of the healed DRFs, pain score and grip strength with the Gartland and Werley's Functional Scoring System and Modified Mayo Scoring System functional scores. The secondary objective was to determine if there is an association between the Gartland and Werley scores and the Modified Mayo scores.

\section{Methods}

From January 2008 to June 2009, we did a retrospective review of 135 patients with closed DRFs that were treated in our institution within 3 weeks of their injury. We excluded skeletally immature patients (age below 18 years) or those patients with congenital anomaly of wrist, radiocarpal arthritis, open fractures, neurovascular injuries, associated injuries of ipsilateral upper limb, bilateral wrist injury, mental incompetence, other systemic injuries and patients who were initially managed elsewhere. Excluding these patients, we had 62 patients that fulfilled our criteria and thus were included in our study. Out of these 62 patients, only 18 patients had adequate follow-up. The indications for operative treatment or reduction of the fractures were unacceptable displacement of the fractures. We included all modes of treatment for the displaced fractures of the distal radius for this study: open reduction-internal fixation, closed reduction with and without pins or external fixation, and closed reduction-cast immobilization. Casting was usually the method of choice if the fracture configuration was stable on closed reduction. Operative treatment was usually done if instability of the fracture was observed. Instability factors were usually based on the criteria of LeFontaine et al. ${ }^{18}$ The presence of three or more (out of five) would necessitate operative treatment. The method of treatment would be dependent on the fracture configuration or the surgeon's preference. Our outcome measures were the functional scores of Gartland and Werley and the Modified Mayo Score. Our independent variables were Sarmiento's modification of the Lindstrom's scoring system and the radiologic parameters: radial height, radial tilt, volar tilt, ulnar variance and gap, regardless of the method of treatment.

All 18 patients were right handed. There were 12 males and 6 females. The injuries were sustained as a result of high-velocity road traffic accident (3 cases), moderate velocity fall and pedestrian injury (7 cases) and low velocity fall (8 cases). Five had AO type A and remaining 13 had AO type $\mathrm{C}$ fractures. Eleven fractures were dorsally displaced, remaining 7 volarly displaced. The demographic characteristics of the patients are in Table 1.

Table 1. Demographic characteristics of patients with distal third radius fractures

\begin{tabular}{|c|c|}
\hline \multicolumn{2}{|l|}{ Age (years) } \\
\hline Mean (range) & $42(21-78)$ \\
\hline \multicolumn{2}{|l|}{ Sex } \\
\hline Male & 12 \\
\hline Female & 6 \\
\hline \multicolumn{2}{|l|}{ Involvement of Dominant Hand } \\
\hline Yes & 10 \\
\hline No & 8 \\
\hline \multicolumn{2}{|l|}{ Mechanism of Injury } \\
\hline High & 3 \\
\hline Moderate & 7 \\
\hline Low & 8 \\
\hline \multicolumn{2}{|l|}{ AO-ASIF Classification } \\
\hline AO A1 & 1 \\
\hline AOA2 & 2 \\
\hline AOA3 & 2 \\
\hline $\mathrm{AOC1}$ & 3 \\
\hline AOC2 & 9 \\
\hline AOC3 & 1 \\
\hline \multicolumn{2}{|l|}{ Displacement } \\
\hline Volar & 7 \\
\hline Dorsal & 11 \\
\hline \multicolumn{2}{|l|}{ Operative treatment (no. patients) } \\
\hline $\mathrm{CR}+$ Cast & 4 \\
\hline CR+Multiple pin & 3 \\
\hline CR+ Multiple pin + external fixator & 3 \\
\hline ORIF + plate & 6 \\
\hline ORIF +Multiple pin + external fixator & 2 \\
\hline
\end{tabular}

$C R$ - closed reduction; ORIF - open reduction, internal fixation

After the initial management, x-rays were taken, evaluated and scored using Sarmiento et al.'s modification of Lidstrom's scoring system. ${ }^{19}$ Thus, patients were categorized having excellent (0), good (1-3), fair (4-6), or poor (7-12) reduction. All those patients with an excellent or good x-ray score or articular gap less than $2 \mathrm{~mm}$ were considered to have acceptable reduction and those who had fair or poor $\mathrm{x}$ ray score or articular gap of more than $2 \mathrm{~mm}$ were considered to have unacceptable reduction. In Sarmiento's 
modification of the Lidstrom's scoring system, the lower the radiologic parameter score, the better the radiologic outcome.

We followed up these patients at 1.5 and 3 months and evaluated them both clinically for visual analog scale (VAS) score, wrist range of motion, grip strength of the involved and uninvolved hands using a dynamometer with the arm adducted at the patient's side and the elbow flexed to $90^{\circ}$, and radiologically for radial height $(\mathrm{RH})$, radial tilt (RT), volar tilt (VT), ulnar variance (UV) and articular gap. Radiographic parameters, in standard views (PA and lateral), were as follows: radial height: distance between the tip of the styloid process and most proximal point of the articular surface of the radius; radial tilt: the inclination of the articular surface of the radius in the frontal plane; volar tilt: the inclination of the articular surface of the radius in the sagittal plane (positive values when it is volar and negative values when it is dorsal); ulnar variance: the distance between the most proximal point of the articular surface of the radius and the ulnar head (positive values when the ulna is more distal than the radius and negative values when it is more proximal); functional status, disability and return to pre-injury status were also determined. The evaluation of the results was based on the Gartland and Werley's Functional Scoring System, ${ }^{20}$ which has four categories: excellent (0-2), good (3-8), fair (9-14), and poor (15 and above). We also evaluated patients using the Modified Mayo Scoring System and categorized them into four groups: excellent (91-100), good (81-90), fair (65-80), and poor $(<64)$. The higher the GW score, the better the functional outcome.

\section{Postoperative management}

Regardless of the treatment options, all patients underwent similar postoperative rehabilitation protocol of the department: Active and Passive ROME's (Range Of Motion Exercises) (6 pack exercises) for thumb and digits were started as soon as pain permits for half an hour three times a day, usually within the first few days postoperatively. Patients with open reduction and internal fixation with plate and screws had their wrists mobilized within one week of surgery. In 6 weeks post-operation, cast or external fixator were removed after evaluating the patient clinically and radiologically. K-wires were removed at 8 weeks post-op. A well-molded wrist immobilization splint was fitted to wear between exercise sessions and at night. At 8 weeks, wrist immobilization splint was gradually weaned off and active and passive ROMEs were continued.

\section{Data analysis}

All data were encoded in Microsoft Excel and analyzed using STATA ver 10 (STATA, TX, USA). Preoperative and postoperative radiologic parameters (on latest follow-up) were tested for significant differences using the t-test. Tests of association were carried using the Pearson's correlation test between radiologic parameters and outcomes assessment. Significance level was set at $\mathrm{p} \leq 0.05$.

\section{Results}

In our series, a total of 18 distal radius fractures in 18 adults were evaluated. All 18 patients followed up at 1.5 and 3 months at our outpatient clinic for clinical and radiological evaluation. All fractures healed without the need for any additional surgical procedures. The radiological parameters improved from preoperative to immediate postoperative $x$ ray and all parameters remained the same until 3 months follow up (Table 2). All radiologic parameters significantly improved from preoperative status except for volar tilt and ulnar variance. However, these parameters were still within the range of acceptable measurements. The mean radiologic scoring system according to Sarmiento's modification of the Lindstrom score was $2.5 \pm 1.6$ at 1.5 months and $2.5 \pm 1.9$ at 3 months. There was no significant difference between the two scores $(p=0.83)$.

Table 2. Radiologic parameter preoperatively and at three months postoperatively

\begin{tabular}{lccl}
\hline \multicolumn{1}{c}{ Parameter } & Pre-op & Post-op & p-value* \\
\hline $\begin{array}{l}\text { Radial Height } \\
\text { (mm, SD) }\end{array}$ & $6.4 \pm 2.9$ & $10.1 \pm 1.9$ & 0.005 \\
$\begin{array}{l}\text { Radial Tilt } \\
\text { (degrees, SD) }\end{array}$ & $13.5 \pm 1.9$ & $18.7 \pm 3.9$ & 0.0003 \\
$\begin{array}{l}\text { Volar Tilt } \\
\text { (degrees, SD) }\end{array}$ & $-0.8 \pm 22.4$ & $2.1 \pm 9.8$ & 0.61 \\
$\begin{array}{l}\text { Ulnar Variance } \\
\text { (mm, SD) }\end{array}$ & $1.6 \pm 3.6$ & $0.14 \pm 1.7$ & 0.17 \\
$\begin{array}{l}\text { Gap } \\
\text { (mm, SD) }\end{array}$ & $0.69 \pm 0.75$ & $0.15 \pm 0.55$ & 0.05 \\
\hline
\end{tabular}

mm-millimeter; SD-standard deviation

${ }^{*}$ t-test, $p$-value significant at $\leq 0.05$

Grip strength improved from $50.3 \pm 18.1 \%$ of the contralateral at 1.5 months to $70.33 \pm 11.2 \%$ at 3 months follow up. This was significant $(\mathrm{p}=0001)$. A higher grip score was also associated with a higher Modified Mayo Wrist score $\left(\mathrm{r}^{2}=0.51, \mathrm{p}=0.03\right)$ and a better Gartland and Werley Score $\left(r^{2}=-0.70, p=0.001\right)$. Visual Analogue Scale (VAS) for pain also improved from $2.8 \pm 1.8$ at 1.5 months follow-up to $1.3 \pm 1.2$ at 3 months follow-up $(p=0.003)$. Lower pain scores were also associated with a higher Modified Mayo Wrist score $\left(\mathrm{r}^{2}=0.52, \mathrm{p}=0.03\right)$, but not with a better Gartland and Werley Score.

There was no association between the x-ray score (Sarmiento's modification of the Lindstrom score) and the functional outcome scores of Modified Wrist Mayo and Gartland and Werley score ( $\mathrm{p}=0.53$ and 0.21 , respectively).

Overall, the average Modified Mayo wrist score was 77.5 and the average Gartland and Werley score was 2.1. Only 6 of 18 patients had good outcome, with no excellent outcome using the Modified Mayo wrist score, while 11 out of 18 had an excellent to good outcome using the Gartland 
and Werley score. There was however, a significant correlation between the Modified Mayo Wrist score and the Gartland and Werley score in terms of final functional outcome $\left(\mathrm{r}^{2}=-0.81, \mathrm{p}=0.0001\right)$. Higher Mayo Wrist scores correlated with better Gartland and Werley scores.

\section{Complications}

Of 18 patients, 2 developed pin tract infection, (both treated by closed reduction and external fixator), which subsided after two weeks of oral antibiotics and daily pin tract care.

\section{Discussion}

The management of distal radius fractures has evolved in recent years and the radiologic parameters on fracture reduction have been one of the cornerstones adapted in predicting functional outcome.

Various studies ${ }^{21-23}$ on patients with distal radius fracture fixations have reported complications related to hard wares, loose wires, loss of reduction, radial sensory numbness or paresthesias, extensor tenosynovitis, extensor tendon rupture and post traumatic arthritis. In this series, we only observed 2 pin tract infections. We attributed this to small sample size and short duration of follow up. However, no patients in our series underwent any secondary procedures.

Evaluating predictors of functional outcomes after DRFs is difficult because of variability in the treatment methods, differences in surgeon expertise, the lack of a well-defined study protocol to collect all relevant data, and inconsistency in the follow-up times. The outcome variables were based on data from the Gartland and Werley and Modified Mayo scoring system, both of which has been shown to be a reliable and valid outcome tool for the upper extremity.

In this study, higher grip strength was associated with a higher level of functioning, based on the Modified Mayo Wrist Score and Gartland and Werley scores. Higher grip scores may indicate that the fractures are already healed and that they approximate the normal grip of the contralateral side. This may in turn provide a functionality of the involved extremity. Lower levels of pain were also shown to be associated with a higher Modified Mayo Wrist Score, but not the Gartland and Werley score. Less pain with hand use may imply increase in function as measured by the MMWS or the Garland and Werley scores. However, the nonassociation of pain with the Gartland and Werley scores may be explained by the different rating system used. While VAS for pain was measured using a 0 to 10 point scale, the Gartland and Werley scoring expressed pain as "none" to "occasional" to "often". The categorical description of pain may be different and are prone to misinterpretation by the patient, compared to a 0 to 10 scaling by using the VAS. Also, the other parameters of the Gartland and Werley scores might have affected the overall score.
Outcome questionnaires have been used in other studies $^{3,24-30}$ evaluating DRF, and these questionnaires provide a robust and sensitive dependent variable for constructing a predictive model that cannot be assessed via objective measures alone. ${ }^{29,31}$

Previous studies ${ }^{27,32-34}$ have shown that variability in treatment type has an important effect on the outcomes of DRF treatment. Therefore, consistency in using one surgical technique would be an ideal situation to define the final functional outcome. However, we included all modes of treatment so as to increase the sample size, which was still not adequate. Regardless of treatment modality, the objective of any surgical intervention for distal radius fractures was to restore anatomical alignment and establish anatomic acceptability, and restoration of function. In our series, we had two physiologically old patients whom we treated by closed reduction and long arm casting as we thought they were functionally less demanding, as suggested by Young. ${ }^{23}$ At 3 months follow up, both of these patients rated good to excellent result by both Gartland and Werley's and Modified Mayo score. Although the authors agree that three months follow up is too short to evaluate functional outcome, this study may represent the initial or preliminary results and association of radiologic parameters with functional outcomes. An outcome study ${ }^{1}$ has shown that patients with DRFs reach a very high level of clinical functioning at 12 months and have little functional improvement thereafter. It was also observed that recovery at 3 and 6 months were not statistically significant. A longer follow-up is needed to determine long-term outcomes of fracture fixation of DRFs. This represents one of the limitations of this study together with the small sample size. This might be a reason why the results of the study showed no correlation. However, non-correlation between the radiologic parameter of Sarmiento's modification of the Lindstrom score may mean that this may not be the ideal radiologic parameter to use. The limitations in the radiologic parameters may not be suitable in predicting outcomes in distal radius fracture treatment. Also, this same limitation may also be present in using the Gartland and Werley scores as well as the Modified Mayo Wrist Score. Perhaps using a validated patient-oriented measure like the DASH score may be more appropriate. ${ }^{35}$ However, application of this outcomes measure will need cultural translation for it to be applicable to the population where it will be used. Another limitation may be the mode of treatment for the DRF. Certain treatments such as stable internal fixation with plate and screws may have an early good functional outcome compared to external fixation because of early motion. This may have an effect on our early evaluation at 3 months for our functional outcome. Although confirmation of recent literature has been shown in this study that radiographic outcomes does not necessarily correlate to functional outcome, the results in this study can contribute to the 
existing knowledge on distal radius fracture fixation and evaluation. Although radiographic evaluation of fracture fixation will be one of the mainstays of fracture treatment, this should be combined with the functional outcome of patients with such fractures. Future studies may help in defining the role of such radiographic assessments on distal radius fracture fixations and their relationship with functional outcomes.

\section{Conclusion}

There was no correlation between the radiologic scoring of distal radius fractures after treatment to the functional outcome scoring according to the Gartland and Werley and Modified Mayo score.

\section{References}

1. Chung KC, Kotsis SV, Kim HM. Predictors of functional outcomes after surgical treatment of distal radius fractures. J Hand Surg Am. 2007; 32(1):76-83.

2. Altissimi M, Antenucci R, Fiacca C, Mancini GB. Long-term results of conservative treatment of fractures of the distal radius. Clin Orthop Relat Res. 1986; (206):202-10.

3. Anzarut A, Johnson JA, Rowe BH, Lambert RG, Blitz S, Majumdar SR. Radiologic and patient-reported functional outcomes in an elderly cohort with conservatively treated distal radius fractures. J Hand Surg Am. 2004; 29(6):1121-7.

4. Field J, Warwick D, Bannister GC, Gibson AG. Long-term prognosis of displaced Colles' fracture: a 10-year prospective review. Injury. 1992; 23(8):529-32.

5. Cassebaum WH. Colles' fracture, a study of end results. J Am Med Assoc. 1950; 143(11):963-5.

6. Sarmiento A, Pratt GW, Berry NC, Sinclair WF. Colles' fractures. Functional bracing in supination. J Bone Joint Surg Am. 1975; 57(3):3117.

7. Marsh JL, Buckwalter J, Gelberman R, et al. Articular fractures: does an anatomic reduction really change the result? J Bone Joint Surg Am. 2002; 84-A(7):1259-71.

8. McQueen M, Caspers J. Colles fracture: does the anatomical result affect the final function? J Bone Joint Surg Br. 1988; 70(4):649-51.

9. Goldfarb CA, Rudzki JR, Catalano LW, Hughes M, Borrelli J Jr. Fifteenyear outcome of displaced intra-articular fractures of the distal radius. J Hand Surg Am. 2006; 31(4):633-9.

10. Kreder HJ, Hanel DP, Agel J, et al. indirect reduction and percutaneous fixation versus open reduction and internal fixation for displaced intraarticular fractures of the distal radius: a randomised, controlled trial. J Bone Joint Surg Br. 2005; 87(6):829-36.

11. Orbay JL, Fernandez DL. Volar fixation for dorsally displaced fractures of the distal radius: a preliminary report. J Hand Surg Am. 2002; 27(2):205-15

12. Knirk JL, Jupiter JB. Intra-articular fractures of the distal end of the radius in young adults. J Bone Joint Surg Am. 1986; 68(5):647-59.

13. Trumble TE, Schmitt SR, Vedder NB. Factors affecting functional outcome of displaced intra-articular distal radius fractures. J Hand Surg Am. 1994; 19(2):325-40.

14. MacDermid JC, Roth JH, Richards RS. Pain and disability reported in the year following a distal radius fracture: a cohort study. BMC Musculoskelet Disord. 2003; 4:24.
15. McKay SD, MacDermid JC, Roth JH, Richards RS. Assessment of complications of distal radius fractures and development of a complication checklist. J Hand Surg Am. 2001; 26(5):916-22.

16. Stewart HD, Innes AR, Burke FD. Functional cast-bracing for Colles' fractures. A comparison between cast-bracing and conventional plaster casts. J Bone Joint Surg Br. 1984; 66(5):749-53.

17. Tsukazaki T, Takagi K, Iwasaki K. Poor correlation between functional results and radiographic findings in Colles' fracture. J Hand Surg Br. 1993; 18(5):588-91.

18. Lafontaine M, Hardy D, Delince P. Stability assessment of distal radius fractures. Injury. 1989; 20(4):208-10.

19. Lidstrom A. Fractures of the distal end of the radius. A clinical and statistical study of end results. Acta Orthop Scand Suppl. 1959; 41:1-118.

20. Gartland JJ Jr, Werley CW. Evaluation of healed Colles' fractures. J Bone Joint Surg Am. 1951; 33-A:895-907.

21. Benson LS, Minihane KP, Stern LD, Eller E, Seshadri R. The outcome of intra-articular distal radius fractures treated with fragment-specific fixation. J Hand Surg Am. 2006; 31(8):1333-9.

22. Rozental TD, Beredjiklian PK, Bozentka DJ. Functional outcome and complications following two types of dorsal plating for unstable fractures of the distal part of the radius. J Bone Joint Surg Am. 2003; 85$\mathrm{A}(10): 1956-60$.

23. Young BT, Rayan GM. Outcome Following Nonoperative Treatment of Displaced Distal Radius Fractures in Low-Demand Patients Older Than 60 Years. J Hand Surg Am. 2000; 25(1):19-28.

24. Beaulé PE, Dervin GF, Giachino AA, Rody K, Grabowski J, Fazekas A. Self-reported disability following distal radius fractures: the influence of hand dominance. J Hand Surg Am. 2000; 25(3):476-82.

25. Catalano LW 3rd, Cole RJ, Gelberman RH, Evanoff BA, Gilula LA Borrelli J Jr. Displaced intra-articular fractures of the distal aspect of the radius. Long-term results in young adults after open reduction and internal fixation. J Bone Joint Surg Am. 1997; 79(9):1290-302.

26. Fernandez JJ, Gruen GS, Herndon JH. Outcome of distal radius fractures using the Short Form 36 Health Survey. Clin Orthop Relat Res. 1997; (341):36-41.

27. Gliatis JD, Plessas SJ, Davis TR. Outcome of distal radial fractures in young adults. J Hand Surg Br. 2000; 25(6):535-43.

28. Karnezis IA, Fragkiadakis EG. Association between objective clinical variables and patient-rated disability of the wrist. J Bone Joint Surg Br. 2002; 84(7):967-70.

29. MacDermid JC, Richards RS, Donner A, Bellamy N, Roth JH Responsiveness of the Short From-36, disability of the arm, shoulder, and hand questionnaire, patient-rated wrist evaluation, and physical impairment measurements in evaluating recovery after a distal radius fracture. J Hand Surg Am. 2000; 25(2):330-40.

30. MacDermid JC, Donner A, Richards RS, Roth JH. Patient versus injury factors as predictors of pain and disability six months after a distal radius fracture. J Clin Epidemiol. 2002; 55(9):849-54.

31. Amadio PC, Silverstein MD, Ilstrup DM, Schleck CD, Jensen LM. Outcome after Colles Fracture: the relative responsiveness of three questionnaires and physical examination measures. J Hand Surg Am. 1996; 21(5):781-7.

32. Wilson FC, Dirschl DR, Bynum DK. Fractures of the radius and ulna in adults: an analysis of factors affecting outcome. Iowa Orthop J. 1997; 17:14-9.

33. Aro HT, Koivunen T. Minor axial shortening of the radius affects outcome of Colles' fracture treatment. J Hand Surg Am. 1991; 16(3):392-

34. Carter PR, Frederick HA, Laseter GF. Open reduction and internal fixation of unstable distal radius fractures with a low-profile plate: a multicenter study of 73 fractures. J Hand Surg Am. 1998; 23(2):300-7.

35. Hudak PL, Amadio PC, Bombardier C. Development of an upper extremity outcome measure: the DASH (disabilities of the arm, shoulder and hand) [corrected]. The Upper Extremity Collaborative Group $\begin{array}{lllll}\text { (UECG). Am J Ind } & \text { Med. 1996; } 602-8\end{array}$ 